\title{
Contribution of Information and Communications Technologies (ICTs) to Improve Education Service Delivery in Tanzania: An Overview
}

\author{
${\text { Restituta Mushi }{ }^{1} \text {, Manoj Maharaj }}^{2}$ \\ ${ }^{1}$ University of Kwazulu-Natal, Private Bag X01, Pietermaritzburg, 3209, South Africa. \\ restymushi@gmail.com \\ ${ }^{2}$ University of Kwazulu-Natal, Private Bag X54001, Durban, 4000, South Africa. \\ maharajms@gmail.com
}

\begin{abstract}
Advancement in technology has changed the way people think, live and engage in socio-economic development. Information and Communication Technologies (ICTs) have played and continue to play a key role in education and in the education sector. Considering education as key to all aspects of social change, recent studies have shown that ICTs have become an important tool in education for learning, teaching, research, and knowledge acquisition. This paper articulates the contribution of the ICTs in enhancing education provision in Tanzania. Based on literature review, the central question that this paper seeks to address is: What could be the contribution of ICTs in enhancing educational provision and social change in Tanzania? The paper begins by offering an overview of ICTs and their adoption in Tanzania, and then explores the contribution ICTs have made in improving educational service delivery in Tanzania and finally identifying some challenges before drawing conclusions and making some recommendations.
\end{abstract}

Key words: ICTs, MDGs, Tanzania, Education, Socio-economic development

\section{Introduction}

Achieving the Millennium Development
Goals (MDGs) requires a multifaceted approach and a variety of strategies and tools. Macro, mesa and micro-level forces are influential in facilitating or impeding the development process. ICTs have been recognized as playing a key role in a country's economic growth and consequently poverty reduction. If properly implemented, ICTs would improve efficiency, provide access to new markets or services, create new opportunities for income generation and enhance living standards. It is hence natural to attempt to integrate ICTs into a country's education policies and procedures, in the hope that they will lead to a general improvement in the sector.

This paper is set out to articulate the contribution that ICTs have made in the educational sector since the adoption of the MDGs in 2000 in Tanzania. It begins by describing how Tanzania has adopted ICTs in the education sector, what has been done to deploy ICTs in an effort to improve educational services delivery and how this has contributed to the improvement of people's education. Finally, the paper outlines some challenges, prospects and future plans while offering some practical recommendations on how to mitigate challenges and optimize the use of ICTs in the education sector. 


\section{Overall Adoption of ICTs in Tan- zania}

Harrison, Onguko, Ang'ondi, Namalefe, Naseem, \& Wamakote [1] have pointed out that developments in ICTs offer opportunities to stimulate growth and increase efficiencies in various sectors. However, there is need to create an enabling environment that will allow the proper harnessing and utilization of ICTs so as to realize its full potential. In this regard, Tanzania, like many other African countries, has made a deliberate effort to adopted ICTs as an important tool for national development. This is a necessary step because without government's commitment, it is difficult to foster and create an environment for ICTs to be deployed to improve service delivery. According to Swarts \& Wachira [2] the adoption of ICTs in Tanzania can be viewed in various ways.

ICTs have been integrated into various national development policies such as national ICT policy, National Vision 2025, National Strategy for Growth and Reduction of Poverty (NSGRP). In all these policy documents, ICT has been outlined as a powerful development tool in the fight against poverty, ignorance and disease.

Further, government funds have been allocated for ICTs infrastructure and government sets standards to ensure compatibility and encourage all sectors to invest in ICT development. In addition, in cooperation with the UN, Tanzania has established the Tanzania Knowledge Network (TAKNET) for creating, sharing and applying knowledge in education systems and other critical development areas.

Apart from this general adoption of ICTs in Tanzania, more efforts have been expended to formulate a particular ICT policy that guides its utilisation in the education sector. According to URT [3] this policy emphasizes a number of expectations regarding the use of ICTs in education systems. These include:

- The strategic integration of ICTs is expected to improve access and equity to education on one hand, and the quality and relevance of basic education on the other hand.

- ICTs will be used to increase the number and quality of teachers, through improved pre-service and in-service training and better provision of teaching and learning materials.

The adoption of ICT technologies in the country in general and in education sector in particular, sets a base for wider use of ICTs in education. The significance of this contribution is analysed in the following section.

\section{The contribution of ICTs in edu- cational service delivery in Tanzania}

The advancement of technologies, especially ICTs and their contribution to improving education service delivery has been continuously celebrated and appreciated in most parts of the world. Affirming this [4] of the education development centre in Washington DC, contends that 'changes in technology, communication and our knowledge of teaching and learning' has significantly improved the education system in the past few decades. This is true in the context of Tanzania where ICTs have been constantly contributing to the educational service delivery in various levels and various aspects of education system as outlined below.

\subsection{Pedagogical improvement}

This is one area in which ICTs have made a significant contribution. For the past 
few years ICTs have provided strong support to improve and develop the quality of education in terms of pedagogical advancement. With the help of ICTs, teachers have been involved in collaborative projects and development of intervention strategies, which would include teaching partnerships using ICT as a tool. In this regard, the use of word processing, internet and presentations, Novell GroupWise, e-mail software, Moodle and Turnitin have been regarded by [5] as essential and important aspects of ICTs to support teaching activities of academic staff [8] and that e-mail has become an important source of contact especially for student-academic staff interaction. The current study in this regard shows that more than half of the academics acknowledged that ICTs have had a positive impact on their student learning. Social networking tools such as YouTube, blogs, Wikis, Facebook, Twitter and Vimeo (video sharing) have also been deployed by the academics in teaching and learning [6]. Moreover, academic staff have been using ICTs for pedagogical purposes such as searching for information, making presentations, preparing lecture materials, communicating with students and lecturers, etc. [7]. Similarly, [8] it has been noted that Internet was used to deliver courses or lectures to students. Equally, given the increased number of school teachers necessary to meet Education For All, the use of ICTs has helped teachers to meet training targets and also provided them with opportunities to complement in-service training and continuing education for teachers.

\subsection{Improved Learning}

Learning is another aspect to which ICT has a continued contribution. In Tanzania studies have shown that ICT hardware devices such as laptops, printers, radio, television, cellular phones, computer and internet were used by students for learning [9 \& 10]. This means that ICTs have offered great support in tertiary institutions especially when using computers in academic programmes in order to produce good quality research output and learning and also increasing access to distance learning thus bringing educational opportunity to a greater number of people across ages, geographical locations, gender and students with disabilities [8].

Moreover, ICTs have broadened the availability of quality education materials through network technologies. These network technologies allow for interactivity and global reach to enhance customized knowledge sharing of materials in a quick and cost effective manner. In addition, ICT advances have enhanced the learning environment especially to students who are required to have research and critical thinking skills for research and evaluation, given the volumes of information available [11]. With the utilisation of ICTs in education, learners' motivation and engagement have significantly increased. This is because ICTs are also transformational tools which, when used appropriately, can promote the shift to a learner centred environment. ICTs, especially computers and Internet technologies, enable new ways of teaching and learning rather than simply allowing teachers and students to do what they have done before in a better way. ICTs have an impact not only on what students should learn, but it also plays a major role on how the students should learn [12].

\section{Challenges faced in utilising ICT in education.}

While the above sections discussed the positive contribution of ICTs, in reality there are also some outstanding challenges that hinder maximum utilisation of ICTs in the education sector in Tanzania which need particular attention. The first 
challenge is connectivity. As it is in most developing countries, Tanzania suffers from a poor infrastructure for communication, power and transport. Broadband connections are not yet available in most of the areas in the country and the power supply is unreliable. Another challenge has to do with content. Much of the content is available in English and not in Kiswahili which is the local language hence limiting its value to local users and leading to significant user dissatisfaction [13 \& 14]. Further, the majority of Tanzanians have insufficient skills and awareness of ICT facilities and their role in socio-economic development. Also there is a challenge of generation gap where older generation (which includes some decision makers) are not pro-ICTs hence, retarding the effort to maximize the use of ICTs for knowledge gaining and knowledge production [15 \& 16].

\section{Recommendations and conclusion}

This paper was set out to explore the contribution of ICTs in improving education service delivery in Tanzania. It has been found that Tanzania is cognisant of the capacities embedded in the ICTs technologies serving as enabling tools for socioeconomic development in general, and the education sector in particular. In this regard, ICTs have been well adopted as development tools in Tanzania and have been mainstreamed in the education systems. Over the past decade of adoption and utilisation of ICTs, significant improvement of education service delivery is highly noticed. Such contribution ranges from improving teaching and learning, administrative and enhancing quality and access to education. Apart from these improvements, there are noticeable challenges that hinder total harnessing of the potentials of ICTs for education development. To mitigate these challenges and realise maximum utilisation of ICTs in education service delivery, it is recommended that development of local ICTs hardware, software and application be encouraged. Also, the government should establish more strategic approaches to ICTs and better organisation arrangements for implementation. Moreover, ICTs should be strategically integrated into various development initiatives especially in the education sector. Furthermore, the government should promote affordability and access through tax relief, enhancing connectivity, develop local contents, improve skills, planning, and leadership, and cultivate innovative.

\section{References}

[1]. Hennessy, S. Onguko, B. Harrison, D. Ang'ondi, E. K. Namalefe, S. Naseem, A. \& wamakote, L. 2010. Developing the Use of Information and Communication Technology to Enhance Teaching and Learning in East African Schools: Review of the Literature [Online]

<http://www.educ.cam.ac.uk/cen tres/cce/publications/CCE_Repo rt1_LitRevJune0210.pdf>Access ed on 14, March 2013.

[2]. Swarts, P.\& Wachira, E. M. 2010.Tanzania: ICT education situational analysis. Gesci, Global e-Schools and communities initiative. Creative Commons

[3]. URT. 2007. Ministry of education and vocational training (MoEVT) Information \& Communication Technology (ICT) policy for basic education. Dar es Salaam. Tanzania.

[4]. Burns, M. 2011. Distance Education for Teacher Training: Modes, Models, and Methods. Education development centre Inc: Washington DC. 
[5]. Mushi, R. T. Hoskins, R. Bell, F. 2011. Use of Information and Communication Technologies for Teaching. Loyola Journal of Social Sciences 25 (2): 239

[6]. Jones, S., Johnson-Yale, C., Millermaier, S. and Perez, F. S. 2008. Academic work, the internet and US college students. Internet and Higher Education (11): 165-177

[7]. Mushi, R. 2010. Use of information and communication technologies (ICTs) by postgraduate students and academic staff for teaching and learning at the University of KwaZulu-Natal. University of KwaZulu-Natal. South Africa.

[8]. Achimugu, P. Oluwagbemi, O. and Oluwaranti, A. 2010. An evaluation of the impact of ICT diffusion in Nigeria's higher educational institutions. Journal of Information Technology Impact 10(1): 25-34

[9]. Kaino, L. Mtetwa, D. \& Kasanda, C. 2011. ICT research output in higher education institutions: utilization of ICT knowledge at some African Universities.

[10]. Kaino, L. M. 2008. ICT developments, utilization and challenges in International Commission Mathematical Instruction (ICMI) history. Symposium of the $100^{\text {th }}$ anniversary of ICMI, Rome, Italy, 5-8 March, 2008. [Online]<http://www.unige.ch/m ath/EnsMath/Rome2008/ALL/P apers/KAINO.pdf > Accessed on 23 September 2011

[11]. Ul-Amin, S. N. 2009. An Effective use of ICT for Education and Learning by Drawing on Worldwide Knowledge, Research, and Experience: ICT as a
Change Agent for Education [Online] $<$ http://www.nyu.edu/classes/ke efer/waoe/amins.pdf> Accessed on 16 march 2013

[12]. Dzidonu, C. 2010. An analysis of the role of ICTs to achieving the MDGs: a background paper. [Online]<http://unpan1.un.org/in tradoc/groups/public/documents/ $\mathrm{UN}-$

DPADM/UNPAN039075.pdf>

Accessed on 12 March 2013

[13]. Henley, M. 2010. Realising the potential of ICTs in Tanzania: policy briefing. Panos. London. [Online] <http://panos.org.uk/wpcontent/files/201 1/01/panoslondon-ICTs_and_tanzaniapolicy.pdf. Accessed on $18^{\text {th }}$ March 2013

[14]. Tusubira, F. \& Mulira, N. 2004 Integration of ICT in organizations: challenges and best practice recommendations based on the experience of Makerere University and other organizations, Paper presented at the International ICT Conference Held at Hotel Africana, Kampala, Uganda. 5th to 8th September

[15]. International Institute for Communication and DevelopmentIICD. 2007. Annual report [Online]<http://annualreport.iicd .org> Accessed on 10 July 2011

[16]. Kaino, L. M. 2007. The use of Information and Communication Technology (ICT) in learning: students' attitudes in Botswana secondary schools by gender. Research report: Study sponsored by the organization of social science research in Eastern and Southern Africa (OSSREA). 